\title{
Good Samaritan Drug Overdose Act awareness among people who use drugs in British Columbia, Canada
}

\author{
Amiti Mehta, ${ }^{*}$ Amina Moustaqim-Barrette, ${ }^{*}$ Kristi Papamihali, ${ }^{*}$ Jessica Xavier, ${ }^{*}$ Brittany Graham, \\ Sierra Williams, ${ }^{*}$ and Jane A. Buxton*†
}

This article is related directly to the $6^{\text {th }}$ International Law Enforcement $\mathcal{E}$ Public Health (LEPH) Virtual Conference in March 2021.

\begin{abstract}
Introduction: To address the increase in opioid-related overdoses and deaths in Canada the Good Samaritan Drug Overdose Act (GSDOA) was enacted in May 2017. The GSDOA aims to reduce concerns of police attending overdose events and encourage bystanders to call emergency services. This study explores GSDOA awareness and understanding and the factors associated with GSDOA awareness among people who use drugs (PWUD).

Methods: A cross-sectional drug and harm reduction service use survey containing GSDOA-specific questions was conducted from October to December 2019 at 22 harm reduction supply distribution sites across British Columbia. Descriptive analysis and multivariable logistic regression were conducted to assess correlates of GSDOA awareness.

Results: Overall, $54.2 \%(n=315)$ of the eligible study sample $(n=581)$ reported being aware of the GSDOA. Of respondents reporting awareness, $45.2 \%$ and $61.3 \%$, respectively, had a full understanding of when and to whom the GSDOA provides legal protection. In the multivariable model, GSDOA awareness was significantly associated with respondents identifying as cis-men (adjusted odds ratio $(\mathrm{AOR})=2.03$ [95\% CI: 1.30-3.19]); and those who obtained harm reduction supplies frequently (at least a few times/week) compared with those who did not obtain supplies or obtained them less frequently (AOR $=1.78$ [95\% CI: 1.14-2.76]).

Conclusion: More than 2 years after its introduction, approximately half of harm reduction site clients reported being aware of the GSDOA, and, of these, less than two-thirds had a complete understanding of who is legally protected by the GSDOA. Future GSDOA knowledge dissemination should target PWUD who are less engaged with harm reduction services to improve GSDOA awareness and understanding.
\end{abstract}

Key Words Harm reduction; drug overdose; emergency response; police-attended overdose.

\section{INTRODUCTION}

In 2016, more than 2,800 apparent opioid toxicity deaths were reported in Canada, while 991 illicit drug toxicity deaths were reported in British Columbia (BC) (British Columbia Coroners Service, 2021; Government of Canada, 2020). Due to this unprecedented number of opioid overdoses and overdose deaths, a public health emergency was declared in BC in April 2016 (BC Ministry of Health, 2016). Harm reduction services have undergone significant expansion to respond to the increase in overdose deaths, including expansion of naloxone distribution, supervised consumption sites and Overdose Prevention Services, and opioid agonist treatment (Irvine et al., 2019). The combination of these efforts averted more than 3,000 overdose death events between April 2016 and December 2017 (Irvine et al., 2019). Nevertheless, overdose deaths remain high; in fact, in 2020, more than 1,700 illicit drug toxicity deaths were reported in BC, marking the highest number of drug toxicity deaths ever reported in a year (British Columbia Coroners Service, 2021). Additionally, the

Correspondence to: Jane A. Buxton, Professor, University of British Columbia, School of Population and Public Health, BC Centre for Disease Control, 655 West 12 th Avenue, Vancouver, BC V5Z 4R4, Canada. E-mail: jane.buxton@bccdc.ca.

To cite: Mehta, A., Moustaqim-Barrette, A., Papamihali, K., Xavier, J., Graham, B., Williams, S., \& Buxton, J. A. (2021). Good Samaritan Drug Overdose Act aware ness among people who use drugs in British Columbia, Canada. Journal of Community Safety and Well-Being, 6/31, 133-141. https://doi.org/10.35502/jcswb.197

(C) Author(s) 2021. Open Access. This work is distributed under the Creative Commons BY-NC-ND license. For commercial re-use, please contact sales@sgpublishing.ca. g.PUBLISHING Published by SG Publishing Inc. CSKA Official publication of the Community Safety Knowledge Alliance. 
highest rate of drug toxicity deaths to date has been reported in 2021 (i.e., January to May 2021).

Naloxone is an opioid antagonist which has a demonstrated higher affinity for $\mu$ receptors in the brain than opioids and is used to reverse respiratory depression associated with opioid overdose (Foldes et al., 1969; Moustaqim-Barrette, Papamihali, \& Buxton, 2019). Community-based Take Home Naloxone (THN) programs provide naloxone training and kits to those at risk of experiencing or witnessing an overdose, to prepare people to recognize and respond to overdose. Individuals responding to an overdose are encouraged to call emergency services (911), even when naloxone is administered, as the effects of naloxone wear off after 30 to $90 \mathrm{~min}-$ utes and most opioids remain in the body after the effects of naloxone have worn off (Lim et al., 2016). Therefore, there is a risk of the opioid overdose re-occurring or the individual experiencing other adverse effects (Nguyen \& Parker, 2018).

Previous research identified that between $52 \%$ and $75 \%$ of bystanders at overdose events reported concerns about prosecution by the police as a deterrent to calling 911 (CCSA \& CCENDU, 2017). In order to allay fears of police attendance and to encourage bystanders to call emergency services during any type of overdose event, the federal government of Canada enacted the Good Samaritan Drug Overdose Act (GSDOA) in May 2017 (Government of Canada, 2021). The GSDOA provides legal protection against simple possession charges to anyone at the scene of an overdose in possession of drugs for personal use (Government of Canada, 2019). The GSDOA also protects individuals with prior charges including breach of probation, "pre-trial release," "conditional sentences," or "parole" due to drug possession for personal use (Government of Canada, 2019). Table I presents the tenets of the federal GSDOA. Similar laws exist in various states in the United States. While specific tenets may vary based on the jurisdiction, drug-related Good Samaritan Laws generally offer legal protection for simple possession at an overdose event.

Studies evaluating knowledge of jurisdiction-specific drug-related Good Samaritan Laws (GSL) in the United States demonstrated a lack of GSL awareness among people who use drugs (PWUD) (Banta-Green et al., 2011; Evans et al., 2016). A survey conducted in Washington State showed that only one-third of people who used opiates were aware of the law (Banta-Green et al., 2011). A study by Watson et al. (2018) evaluating the drug-related GSL compliance and possession of naloxone among lay responders at the scene of an overdose demonstrated that lay responders with prior knowledge of the law were more likely to have called 911 at overdose events they had witnessed.
Findings from a study conducted by Selfridge et al. (2020) in $\mathrm{BC}$ assessing the experience of youth with police during overdose events demonstrated that youth who use drugs had mixed understanding of the GSDOA. Provincial knowledge dissemination efforts undertaken to improve GSDOA awareness in BC included development and distribution of informative posters and wallet cards through existing harm reduction supply distribution site networks (BCCDC Harm Reduction Services, n.d.). However, the degree to which PWUD are aware of the GSDOA and informed about when and to whom the GSDOA applies remains unclear. The aim of our study was to assess awareness and understanding of the GSDOA by PWUD, and identify factors associated with GSDOA awareness using data from a cross-sectional survey with clients of harm reduction supply distribution sites. Results from this study will help identify targeted interventions to improve knowledge about the GSDOA.

\section{METHODS}

\section{Study Design}

This study used data from the Harm Reduction Client Survey (HRCS), which was introduced in 2012, repeated annually until 2015, and administered again in 2018 and 2019 by the Harm Reduction services of the BC Centre for Disease Control (BCCDC). The cross-sectional survey is administered at harm reduction supply distribution sites across $B C$ and assesses reported substance use and use of harm reduction supplies and services.

The 2019 HRCS was conducted between October and December 2019. The 2019 survey was revised prior to administration to address emerging harm reduction issues and feedback from stakeholders, including PWUD (MoustaqimBarrette, Papamihali, Crabtree, et al., 2019). Questions evaluating respondents' awareness and understanding of the GSDOA were developed based on the review of prior literature and feedback from co-investigators and people with lived or living experience involved in the Professionals for Ethical Engagement of Peers (PEEP) advisory group at BCCDC. These questions were then piloted with PWUD at Vancouver Area Network of Drug Users (VANDU) and added to the 2019 survey.

Methodological details of survey administration, including recruitment, eligibility, and data collection, have been described in prior publications (Karamouzian et al., 2020; Kuo et al., 2014; Moustaqim-Barrette, Papamihali, Crabtree, et al., 2019). A total of 22 harm reduction sites participated in the 2019 survey (Figure 1). In summary, participating sites

TABLE I Tenets of the Canadian Good Samaritan Drug Overdose Act (GSDOA)

\begin{tabular}{|c|c|}
\hline $\begin{array}{l}\text { The GSDOA protects people who overdose, call } 911 \text {, and anyone } \\
\text { present at any type of overdose event from the following charges: }\end{array}$ & $\begin{array}{l}\text { The GSDOA does not protect people who overdose, call } 911 \text {, and anyone } \\
\text { present at any type of overdose event from the following charges: }\end{array}$ \\
\hline \multirow[t]{2}{*}{ Simple possession of drugs (personal use) } & Selling illicit substances (trafficking) \\
\hline & Other offences apart from drug possession \\
\hline $\begin{array}{l}\text { Charges related to simple possession of drugs, } \\
\text { including violation of pre-trial release, probation } \\
\text { order, conditional sentences, or parole. }\end{array}$ & $\begin{array}{l}\text { Other outstanding arrest warrants } \\
\text { Offences not related to simple possession of drugs, including violation } \\
\text { of pre-trial release, probation order, conditional sentence, or parole }\end{array}$ \\
\hline
\end{tabular}




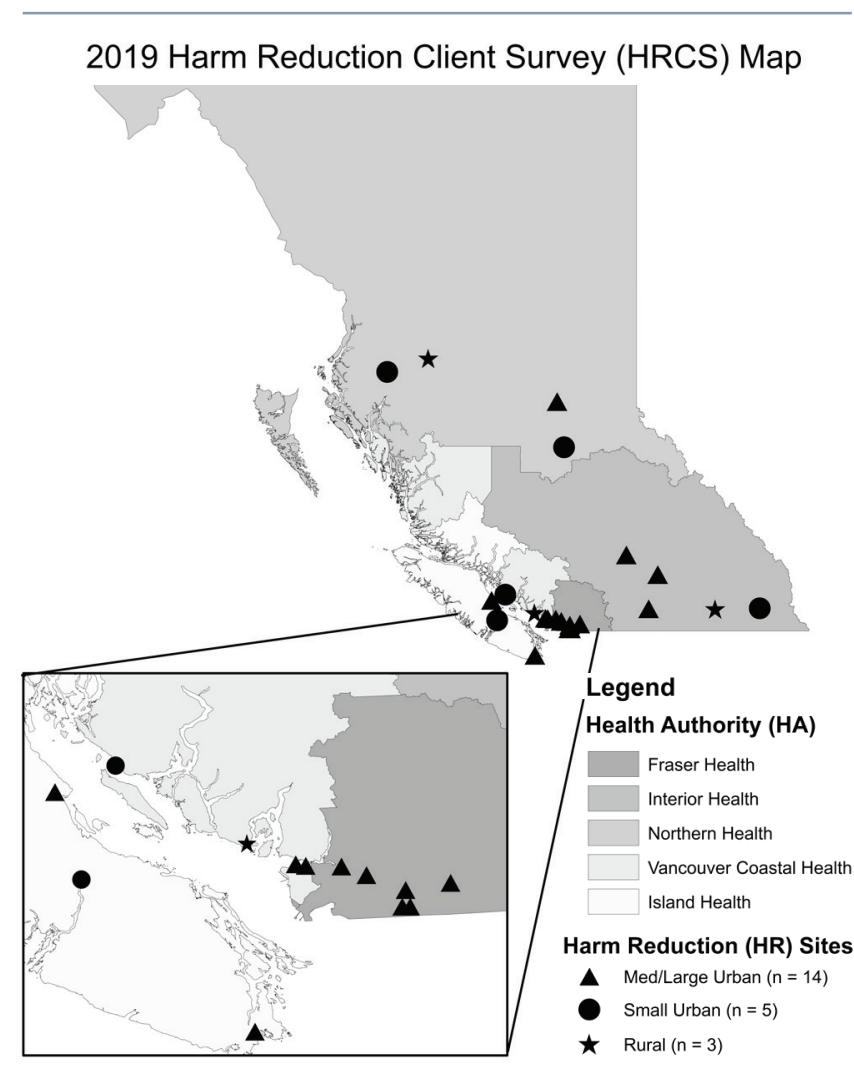

FIGURE 1 Harm reduction supply distribution sites in the 2019 Harm Reduction Client Survey (HRCS)

were provided CA $\$ 5$ for each client interviewed to account for resources and time allocated to administer the four-page survey. Surveys took approximately 10 minutes to complete and participants were offered CA $\$ 10$ for their participation in the 2019 HRCS.

\section{Study Variables}

The outcome variable in this study was "awareness of GSDOA." The question included in the survey was, "Have you heard about the Good Samaritan Drug Overdose Act?" (yes, no). A conceptual framework similar to a prior study was used to categorize the predictor variables (Moustaqim-Barrette, Papamihali, Crabtree, et al., 2019). The predictor variables are shown in Table II.

In order to categorize the respondents' drug use, respondents who reported using opioids (including methadone, morphine, hydromorphone [Dilaudid], oxycodone, fentanyl, buprenorphine, and heroin) in the last 3 days were classified as having "opioid use." The respondents were asked about their drug use in last 3 days to mitigate inaccurate recollections. The reported frequency of obtaining harm reduction supplies in the last 6 months was dichotomized as "frequent" (every day or few times a week) and "occasionally/never" (a few times a month, less than once a month or never).

Respondents' housing status was categorized as "stable housing" if the respondent reported living in a private residence or other residence (including apartment, motel, rooming house, single room occupancy hotel, shelter, social/ supportive housing). "No stable housing" indicated those who reported having no regular place to stay (including being homeless, couch surfing, having no fixed address, living in a tent). The predictor variable assessing whether participants engaged in paid work was categorized "yes" when respondents reported working full-time or part-time or as a paid volunteer.

Urbanicity of sites was determined using a classification system developed by the BC Ministry of Health that combined definitions established by Statistics Canada, taking into account remoteness, population density, and proximity to urban areas (Statistics Canada, 2017; BC Ministry of Health, 2019).

\section{Analytic Sample}

Respondents with missing responses or who responded, "prefer not to say" for the outcome variable were excluded from the descriptive analysis. An "Unknown" category was developed for predictor variables, which included missing, invalid, "prefer not to say" or "I don't know" responses. A complete case analysis (CCA) was used for chi-square, bi-variable, and multivariable logistic regression analyses, excluding participants who were classified as "unknown" for any of the predictor variables.

The analytic sample for the secondary analysis exploring the understanding of when and to whom the GSDOA provides legal protection included only those who reported being aware of the GSDOA. Respondents with missing data or "prefer not to say" to all three questions which assessed when and to whom the GSDOA provides legal protection were excluded from the analysis.

\section{Statistical Analysis}

Descriptive analyses and chi-square tests of independence were conducted to explore the distribution of, and association between, predictor variables and GSDOA awareness. Predictor variables with a $p$ value $<.25$ in chi-square tests of independence and/or deemed to be conceptually relevant were used to build a multivariable logistic regression model. The final model assessing factors associated with GSDOA awareness was identified through a backwards selection approach based on lowest Akaike Information Criterion (AIC). Unadjusted and adjusted odds ratio (OR), 95\% confidence intervals (CI) and $p$ values were reported; $p$ values less than .05 were considered statistically significant.

A secondary analysis was conducted to assess the understanding of when and to whom the GSDOA provides legal protection at overdose events.

$R$ version 4.0.2 was used to conduct the analyses (The $R$ Foundation, 2021). Ethics approval for this study was obtained from Behavioural Research Ethics at the University of British Columbia (Ethics \#H07-00570).

\section{RESULTS}

\section{Study Sample}

Among the 621 respondents to the HRCS, $6.4 \%$ of respondents had missing data or reported "prefer not to say" for the outcome variable, leaving 581 respondents for the descriptive analysis. From this eligible sample, $32.7 \%$ were excluded because of missing or invalid data for the independent study variables. Therefore, the final analytic sample for the analyses 
TABLE II Association between GSDOA Awareness and predictor variables

\begin{tabular}{|c|c|c|c|c|}
\hline & \multirow[b]{2}{*}{ Total $(n, \%)$} & \multicolumn{3}{|c|}{ GSDOA Awareness } \\
\hline & & \multirow{2}{*}{$\begin{array}{c}\text { Aware }(n, \%) \\
(n=315,54.2)\end{array}$} & \multirow{2}{*}{$\begin{array}{c}\text { Not aware }(n, \%) \\
(n=266,45.8)\end{array}$} & \multirow[t]{2}{*}{ Pvalue ${ }^{a}$} \\
\hline & $(n=581,100.0)$ & & & \\
\hline Health authority & & & & 0.013 \\
\hline Fraser & $175(30.1)$ & $106(60.6)$ & $69(39.4)$ & \\
\hline Interior & $104(17.9)$ & $64(61.5)$ & $40(38.5)$ & \\
\hline Island & $57(9.8)$ & $29(50.9)$ & $28(49.1)$ & \\
\hline Northern & $109(18.8)$ & $51(46.8)$ & $58(53.2)$ & \\
\hline Vancouver Coastal & $136(23.4)$ & $65(47.8)$ & $71(52.2)$ & \\
\hline \multicolumn{5}{|l|}{ Urbanicity } \\
\hline Rural & $63(10.8)$ & $26(41.3)$ & 37 (58.7) & 0.214 \\
\hline Small urban & $130(22.4)$ & $65(50)$ & $65(50)$ & \\
\hline Medium/large urban & $388(66.8)$ & $224(57.7)$ & $164(42.3)$ & \\
\hline Gender & & & & 0.016 \\
\hline Woman/gender diverse ${ }^{b}$ & $213(36.7)$ & $104(48.8)$ & $109(51.2)$ & \\
\hline Cis-man & $362(62.3)$ & $206(56.9)$ & $156(43.1)$ & \\
\hline Unknown & $6(1.0)$ & $5(83.3)$ & $1(16.7)$ & \\
\hline \multicolumn{5}{|l|}{ Indigenous self-identification } \\
\hline$Y_{e s}^{c}$ & $238(41.0)$ & $121(50.8)$ & $117(49.2)$ & 0.038 \\
\hline No & $306(52.7)$ & $172(56.2)$ & $134(43.8)$ & \\
\hline Unknown & $37(6.4)$ & $22(59.5)$ & $15(40.5)$ & \\
\hline Age (years) & & & & 0.190 \\
\hline 19 to 29 years & 112 (19.3) & $53(47.3)$ & $59(52.7)$ & \\
\hline 30 to 39 years & $168(28.9)$ & $98(58.3)$ & $70(41.7)$ & \\
\hline 40 to 49 years & $148(25.5)$ & $80(54.1)$ & $68(45.9)$ & \\
\hline 50 years and over & $140(24.1)$ & $75(53.6)$ & $65(46.4)$ & \\
\hline Unknown & $13(2.2)$ & $9(69.2)$ & $4(30.8)$ & \\
\hline Paid work (current) & & & & 0.372 \\
\hline Yes & $129(22.2)$ & 77 (59.7) & $52(40.3)$ & \\
\hline No & $433(74.5)$ & $226(52.2)$ & $207(47.8)$ & \\
\hline Unknown & $19(3.3)$ & $12(63.2)$ & $7(36.8)$ & \\
\hline Housing status (current) & & & & 0.663 \\
\hline Stable housing & $394(67.8)$ & $213(54.1)$ & $181(45.9)$ & \\
\hline No stable housing & $179(30.8)$ & 98 (54.7) & $81(45.3)$ & \\
\hline Unknown & $8(1.4)$ & $4(50.0)$ & $4(50.0)$ & \\
\hline Preferred method of drug use & & & & 0.016 \\
\hline Smoking/inhalation & $361(62.1)$ & $177(49.0)$ & $184(51.0)$ & \\
\hline Injecting & $167(28.7)$ & 110 (65.9) & $57(34.1)$ & \\
\hline Swallowing/snorting/other methods & $26(4.5)$ & $14(53.8)$ & $12(46.2)$ & \\
\hline Unknown & $27(4.6)$ & $14(51.9)$ & $13(48.1)$ & \\
\hline Having a naloxone kit & & & & 0.111 \\
\hline Yes & $399(68.7)$ & $232(58.1)$ & $167(41.9)$ & \\
\hline No & $166(28.6)$ & $72(43.4)$ & $94(56.6)$ & \\
\hline Unknown & $16(2.7)$ & $11(68.8)$ & $5(31.2)$ & \\
\hline
\end{tabular}


TABLE II Continued

\begin{tabular}{|c|c|c|c|c|}
\hline & & & OA Awareness & \\
\hline & Total $(n, \%)$ & Aware (n, \%) & Not aware (n, \%) & Pvalue ${ }^{a}$ \\
\hline & $(n=581,100.0)$ & $(n=315,54.2)$ & $(n=266,45.8)$ & \\
\hline Frequency of obtaining harm reduction supplies (last 6 months) & & & & 0.006 \\
\hline Frequent & $313(53.9)$ & $189(60.4)$ & $124(39.6)$ & \\
\hline Occasional/never & $245(42.2)$ & $116(47.3)$ & $129(52.7)$ & \\
\hline Unknown & $23(4.0)$ & $10(43.5)$ & $13(56.5)$ & \\
\hline Drug use (last 3 days) & & & & 0.451 \\
\hline Opioid use ${ }^{d}$ & $388(66.8)$ & $216(55.7)$ & $172(44.3)$ & \\
\hline No opioid use & $185(31.8)$ & $94(50.8)$ & $91(49.2)$ & \\
\hline Unknown & $8(1.4)$ & $5(62.5)$ & $3(37.5)$ & \\
\hline Witnessed an accidental opioid overdose (last 6 months) & & & & 0.024 \\
\hline Yes & $329(56.6)$ & $194(59.0)$ & $135(41.0)$ & \\
\hline No & $202(34.8)$ & $92(45.5)$ & $110(54.5)$ & \\
\hline Unknown & $50(8.6)$ & $29(58.0)$ & $21(42.0)$ & \\
\hline Experienced an accidental opioid overdose (last 6 months) & & & & 0.086 \\
\hline Yes & $94(16.2)$ & $59(62.8)$ & $35(37.2)$ & \\
\hline No & $442(76.1)$ & $230(52.0)$ & $212(48.0)$ & \\
\hline Unknown & $45(7.7)$ & $26(57.8)$ & $19(42.2)$ & \\
\hline Frequency of drug use (last month)e & & & & 0.563 \\
\hline Every day & $379(65.2)$ & $205(54.1)$ & $174(45.9)$ & \\
\hline A few times a week/month & $154(26.5)$ & $89(57.8)$ & $65(42.2)$ & \\
\hline Unknown & $48(8.3)$ & $21(43.8)$ & $27(56.2)$ & \\
\hline
\end{tabular}

${ }^{a}$ Chi-square tests excluded participants with unknown independent variables

${ }^{b} G e n d e r$ diverse includes participants who identified as trans men, trans women and gender non-conforming

"Yes" to Indigenous self-identification included participants who identified as First Nations, Invit or Métis

d"Opioid Use" referred to use of methadone, morphine, hydromorphone [Dilaudid], oxycodone, fentanyl, and/or heroin in the last 3 days

eFrequency of using drugs by any mode (excluding cannabis, alcohol, or tobacco)

GSDOA = Good Samaritan Drug Overdose Act.

consisted of 391 respondents (67.3\% of all eligible respondents) (Figure 2).

A total of 315 respondents who reported being aware of the GSDOA were retained for the secondary analysis. From this eligible sample, $13.0 \%$ and $13.7 \%$ of the respondents were excluded from analysis due to missing data or "prefer not to say" as a response for the questions assessing to whom and when the GSDOA provides legal protection, respectively. Therefore, the final analytic sample for questions assessing knowledge of to whom and when the GSDOA provides legal protection was comprised of 274 respondents and 272 respondents, respectively.

\section{Demographics of the Study Sample}

The eligible study sample was comprised of 581 respondents (Table II). A large proportion of the respondents were cis-men $(62.3 \%)$, had stable housing $(67.8 \%)$, had no paid work $(74.5 \%)$, did not identify as Indigenous (52.7\%), were aged 30 to 49 years $(54.4 \%)$, obtained services in medium or large urban areas $(66.8 \%)$, and accessed services from the Fraser Health region (30.1\%). In terms of uptake of harm reduction services, $68.7 \%$ reported having a naloxone kit and $53.9 \%$ reported obtaining harm reduction supplies frequently. The majority of respondents reported: using opioids $(66.8 \%)$, smoking or inhalation as their preferred method of drug use $(62.1 \%)$, and using drugs every day (65.2\%). Although $56.6 \%$ of respondents had witnessed an accidental opioid overdose, only $16.2 \%$ reported having experienced one.

\section{Participant Awareness of the GSDOA}

Stratification of the study variables by GSDOA awareness can be found in Table II. The prevalence of GSDOA awareness among cis-men was $56.9 \%$, compared with $48.8 \%$ among women and gender diverse participants (trans men, trans women, gender non-conforming). GSDOA awareness was most common among respondents who reported having paid work $(59.7 \%)$, were aged 30 to 39 years $(58.3 \%)$, accessed services in the Interior Health $(61.5 \%)$ or Fraser Health $(60.6 \%)$ regions, and accessed services in medium or large urban areas (57.7\%). GSDOA awareness was higher among those who 


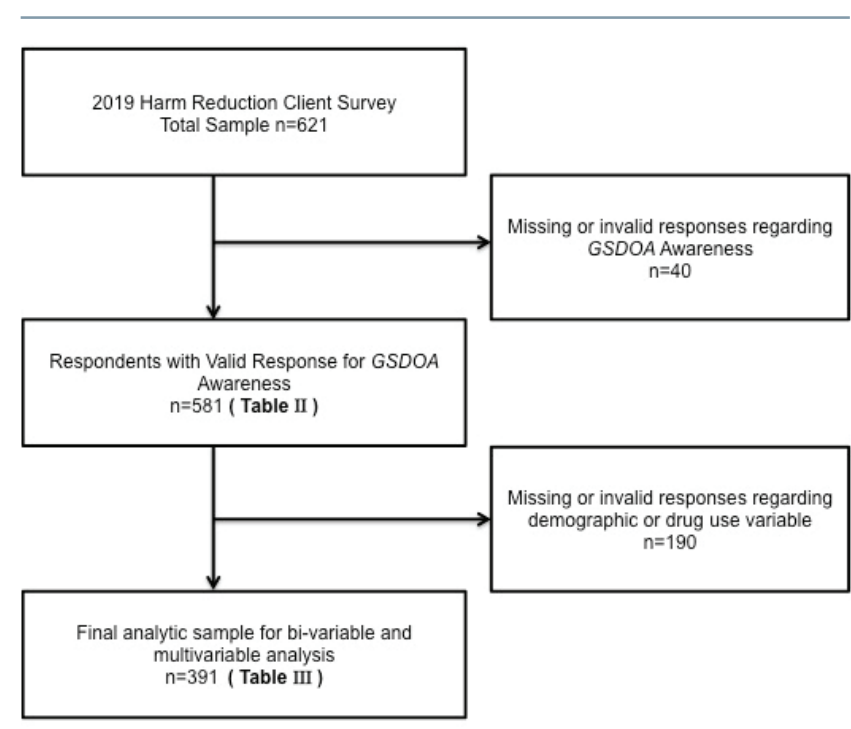

FIGURE 2 Study sample from HRCS 2019 to assess association between Good Samaritan Drug Overdose Act (GSDOA) awareness and independent variables among the clients of harm reduction site clients.

used opioids in the last 3 days (55.7\%); and prefer injecting as their method of drug use $(65.9 \%)$. GSDOA awareness was higher among those who reported having a naloxone kit $(58.1 \%)$ and those who obtained harm reduction supplies more frequently in the last 6 months $(60.4 \%)$. High proportions of GSDOA awareness were also reported by those who witnessed $(59.0 \%)$ or experienced $(62.8 \%)$ an opioid overdose in the last 6 months.

\section{Factors Associated with GSDOA Awareness}

The variables frequency of drug use, housing status, paid work, and drug use were excluded from the multivariable analysis due to statistical non-significance based on chi-square tests of independence ( $p$ value $>.25$ ). The variables "urbanicity," "preferred method of drug use" and "experiencing an opioid overdose," were removed from the final model through the stepwise backward selection method. Prior research in $\mathrm{BC}$ has shown that youth who use drugs had a mixed understanding of the GSDOA (Selfridge et al., 2020). Therefore, the variable "age," although not significant, was retained in the analysis on the basis of conceptual relevance and face validity.

Table III provides results from the unadjusted and adjusted logistic regression. After adjusting for all the predictor variables, greater odds of GSDOA awareness were found among cis-men (AOR: 2.03 [95\% CI: 1.30-3.19]) and respondents who obtained harm reduction supplies frequently (AOR: 1.78 [95\% CI: 1.14-2.76]). The multivariable analysis identified that there was regional variation in GSDOA awareness (data not shown).

\section{Participant Understanding of the GSDOA}

Of the 581 study respondents, $54.2 \%$ were aware of the GSDOA (Table II). Only $45.2 \%$ and $61.3 \%$ of respondents who were aware of the GSDOA had a full understanding of when and to whom the GSDOA provides legal protection, respectively (data not shown). A considerable proportion of respondents

TABLE III Logistic regression for the association between GSDOA awareness and predictor variables $(n=391)$

\begin{tabular}{|c|c|c|c|c|}
\hline & Unadjusted OR (95\% Cl) & $P$ value & Adjusted ORa $(95 \% \mathrm{CI})$ & $P$ value \\
\hline \multicolumn{5}{|l|}{ Gender } \\
\hline Woman/gender diverse ${ }^{b}$ & Reference & & & \\
\hline Cis-Man & $1.69(1.12-2.54)$ & 0.01 & $2.03(1.30-3.19)$ & $<0.01$ \\
\hline \multicolumn{5}{|l|}{ Age (years) } \\
\hline 19 to 29 years & Reference & & & \\
\hline 30 to 39 years & $1.82(1.03-3.24)$ & 0.04 & $1.76(0.96-3.26)$ & 0.07 \\
\hline 40 to 49 years & $1.26(0.70-2.28)$ & 0.44 & $1.22(0.65-2.28)$ & 0.54 \\
\hline 50 years and over & $1.55(0.85-2.83)$ & 0.16 & $1.58(0.83-3.03)$ & 0.17 \\
\hline \multicolumn{5}{|c|}{ Frequency of obtaining harm reduction supplies (last 6 months) } \\
\hline Occasional/never & Reference & & & \\
\hline Frequent & $1.80(1.20-2.71)$ & $<0.01$ & $1.78(1.14-2.76)$ & 0.01 \\
\hline \multicolumn{5}{|c|}{ Witnessed an opioid overdose (last 6 months) } \\
\hline No & Reference & & & \\
\hline Yes & $1.67(1.09-2.55)$ & 0.02 & $1.44(0.91-2.27)$ & 0.11 \\
\hline \multicolumn{5}{|l|}{ Having a naloxone kit } \\
\hline No & Reference & & & \\
\hline Yes & $1.48(0.94-2.31)$ & 0.09 & $1.56(0.95-2.55)$ & 0.08 \\
\hline
\end{tabular}

aThe model was adjusted for Indigenous self-identification and regional Health Authority to consider ethnic and geographic variation, respectively. bGender diverse includes participants who identified as trans men, trans women and gender non-conforming

GSDOA = Good Samaritan Drug Overdose Act; $\mathrm{Cl}=$ confidence interval; OR = odds ratio. 
$(40.8 \%)$ incorrectly answered that the GSDOA provides protection for having large amounts of drugs at the scene of an overdose (Table IV). Additionally, 20.4\% of respondents answered that the GSDOA does not provide legal protection for simple possession to anyone present at the scene of an overdose, which is incorrect.

\section{DISCUSSION}

The aim of this study was to assess GSDOA awareness, factors associated with GSDOA awareness, and understanding of the GSDOA among clients of harm reduction supply distribution sites in BC. Approximately half of survey respondents reported being aware of the GSDOA; however, less than half of those who were aware of the GSDOA had a full understanding of when and less than two-thirds had a full understanding of to whom the GSDOA provides legal protection at an overdose event. Our study demonstrated greater odds of GSDOA awareness among cis-men and those who accessed harm reduction supplies frequently in the last 6 months. Although, the GSDOA was enacted in Canada in response to rising opioid overdose deaths, we did not find a significant association between GSDOA awareness and reported opioid use.

Moderate awareness of GSDOA found in the current study is in line with previous findings around drug-related GSL in the United States (Banta-Green et al., 2011; Evans et al., 2016). A study conducted in the state of Rhode Island explored factors associated with drug-related GSL awareness among young adults engaged in non-medical prescription opioid (NMPO) use and found that $45.5 \%$ of respondents were aware of the law (Evans et al., 2016). While factors associated with drug-related GSL awareness in the United States have previously been reported, to our knowledge this study is the first in Canada to conduct a quantitative assessment to assess correlates of GSDOA awareness with a comprehensive sample of PWUD across BC (Evans et al., 2016; Schneider et al., 2020).

We found greater GSDOA awareness among respondents who reported more frequent access to harm reduction services. A study conducted in Maryland, in the United States, demonstrated that individuals who accessed syringe service programs were more likely to have accurate knowledge of the drug-related GSL (Schneider et al., 2020). Also, similar to a study by Evans at al. (2016) which showed high drug-related GSL awareness among those with knowledge of and experience administering naloxone, we found nearly three-quarters of our respondents who reported GSDOA awareness had a naloxone kit. It is likely that increased awareness of the GSDOA can be attributed to the knowledge exchange efforts initiated by harm reduction supply and THN distribution sites during THN training. While harm reduction services represent an important avenue for engagement with people who use drugs, it may be important that outreach also target individuals who are not currently engaged with harm reduction or health services.

Various GSDOA knowledge dissemination efforts have been introduced by Health Canada at a federal level, including posters and videos (Government of Canada, 2018; 2019). In order to promote GSDOA awareness at the provincial level, the BC Centre for Disease Control (BCCDC) undertook additional knowledge dissemination initiatives, including distribution of posters and wallet cards with information about the GSDOA at harm reduction supply distribution sites. These wallet cards and posters are also available for print on the Toward the Heart website (BCCDC Harm Reduction Services, n.d.). Local knowledge dissemination interventions included the distribution of brochures and informational factsheets created by PIVOT legal (PIVOT Equality Lifts Everyone, 2017). Despite these interventions, the current study demonstrates low awareness and understanding of the GSDOA among study participants.

Although this study assesses the awareness and understanding of the GSDOA among PWUD, an important next step would be to assess the impact of the GSDOA in influencing bystanders' willingness to call 911 at overdose events. In June 2016, prior to the enactment of the GSDOA, the BC Emergency Health Services (BCEHS) introduced a policy to not routinely inform police of overdose events. A study conducted by Karamouzian et al. (2019) identified that people who completed naloxone administration forms from BC Take

TABLE IV Knowledge of the Good Samaritan Drug Overdose Act among people who use drugs

\begin{tabular}{|c|c|c|c|c|}
\hline & & No (\%) & Yes (\%) & Unknown (\%) \\
\hline \multicolumn{5}{|c|}{$\begin{array}{l}\text { Part 1: Does the GSDOA protect the following from being arrested for simple } \\
\text { possession of substances at the scene of an overdose? }(n=274)^{a}\end{array}$} \\
\hline (A) & The person who calls 911 & 16.8 & 79.9 & 3.3 \\
\hline (B) & The person who overdoses & 16.1 & 74.8 & 9.1 \\
\hline (C) & Anyone at the scene of an overdose & 20.4 & 70.8 & 8.8 \\
\hline \multicolumn{5}{|c|}{$\begin{array}{l}\text { Part 2: If police arrive at the scene of an overdose, can they arrest a person in the } \\
\text { following situations: }(n=272)^{b}\end{array}$} \\
\hline (A) & $\begin{array}{l}\text { Have large amount of drugs on them or items (e.g., scale) that may look } \\
\text { like they are involved in drug dealing. }\end{array}$ & 40.8 & 54.8 & 4.4 \\
\hline (B) & $\begin{array}{l}\text { Are in red/no-go zone they received for a previous charge that was not } \\
\text { simple drug possession (e.g., theft) }\end{array}$ & 34.2 & 58.5 & 7.4 \\
\hline & $\begin{array}{l}\text { Have an outstanding warrant for something other than simple drug } \\
\text { possession (e.g., theft) }\end{array}$ & 30.1 & 64.0 & 5.9 \\
\hline
\end{tabular}

aYes is the correct answer for all the questions in Part 1

bYes is the correct answer for all the questions in Part 2 
Home Naloxone (THN) program reported two main reasons for not calling 911: (1) perception that the overdose situation was under control; (2) fear of police presence at overdose events. However, concerns about police presence as a reason for not calling 911 decreased from $29.9 \%$ in 2016 to $8.3 \%$ in 2018 (Moustaqim-Barrette, Papamihali, \& Buxton, 2019). This suggests that one or a combination of the BCEHS policy and the GSDOA may reduce concerns of police attendance at an overdose and encourage bystanders to call 911. Research from the United States evaluating 911 calling behaviour and knowledge of GSL suggests that respondents with a correct understanding of GSL are three times more likely to call 911 at the scene of an overdose, compared with individuals with an incorrect understanding (Jakubowski et al., 2018). Similarly, a study assessing GSDOA awareness, phone possession and Take Home Naloxone kit possession among PWUD who were released from correctional facilities in BC found that $99 \%$ of the respondents who reported being aware of GSDOA would call 911 at overdose events (McLeod et al., 2021). However, it is important to note that, despite these study findings, awareness of the GSDOA may not always be associated with a higher likelihood of calling 911. As previous research has indicated, PWUD continue to have concerns surrounding calling 911, despite being aware of the GSDOA (Butler-McPhee et al., 2020; Koester et al., 2017; Latimore \& Bergstein, 2017). Future research and initiatives should focus on increasing awareness and understanding of the protection offered through the GSDOA as well as identifying and addressing ongoing barriers to calling 911 at overdose events in BC. Our findings suggest that further efforts are needed for more complete knowledge dissemination, including targeting populations of PWUD who may not access harm reduction services.

There are some limitations to the current study. Limitations associated with the sample data, study design, and data collection methodology have been elaborated on in previous studies (Moustaqim-Barrette, Papamihali, Crabtree, et al., 2019). Using a convenience-sampling strategy to recruit study participants likely has an effect on the generalizability of study results. The study sample may not be representative of the entire population of PWUD in BC. This study was conducted with clients of harm reduction services and likely does not reflect the knowledge of PWUD who are less engaged with services in BC. The information collected in the 2019 HRCS may also be subject to social desirability bias.

\section{CONCLUSION}

More than 2 years after its introduction, awareness of the GSDOA and understanding of the legal protections it provides is limited among clients accessing harm reduction services in British Columbia. Further knowledge dissemination efforts to improve GSDOA awareness and understanding are necessary. Future research should examine the effectiveness of the GSDOA in achieving its intended purpose to encourage bystander response and timely emergency response to overdose events.

\section{ACKNOWLEDGEMENTS}

We would like to thank the study participants and harm reduction site coordinators and staff for their assistance with survey implementation and data collection. The authors respectfully acknowledge that they live and work on the unceded traditional territories of the $\mathrm{x}^{\mathrm{w}} \mathrm{m} \partial \theta \mathrm{kw}$ əy Skwww u7mesh (Squamish), and Səlỉ lwətał (Tsleil-Waututh) Nations and that the Harm Reduction Client Survey was conducted across the unceded traditional territories of 198 First Nations. This work was supported by the Health Canada's Substance Use and Addictions Program (Grant 1819-HQ-000054). The funders had no role in the study analysis or preparation of the manuscript. The corresponding author had full access to all the data in the study and had final responsibility for the decision to submit for publication.

\section{CONFLICT OF INTEREST DISCLOSURES}

The authors have no actual or potential conflicts of interest to declare.

\section{AUTHOR AFFILIATIONS}

*British Columbia Centre for Disease Control, Vancouver, BC, Canada; ${ }^{\dagger}$ School of Population and Public Health, University of British Columbia, Vancouver, BC, Canada

\section{REFERENCES}

Banta-Green, C. J., Kuszler, P. C., Coffin, P. O., \& Schoeppe, J. A. (2011). Washington's 911 Good Samaritan Drug Overdose Law-Initial evaluation results. Alcohol \& Drug Abuse Institute, University of Washington. https://adai.uw.edu/pubs/infobriefs/ ADAI-IB-2011-05.pdf

BC Ministry of Health. (2016, April 14). Provincial health officer declares public health emergency. https://news.gov.bc.ca/releases/2016 hlth0026-000568

BC Ministry of Health. (2019). Health Boundaries, Version 2018, Project Summary Report. Canadian Agency for Drugs and Technologies in Health 2018. Funding and Management of Naloxone Programs in Canada. Canadian Agency for Drugs and Technologies in Health (CADTH), 67.

BCCDC Harm Reduction Services. (n.d.). Good Samaritan Drug Overdose Act. https://towardtheheart.com/assets/uploads/1526595325 dttSdJc37OH9Y8aecNPDolPIR5KsP2h7KaWZcgE.pdf

British Columbia Coroners Service. (2021). Illicit drug toxicity deaths in BC January 1, 2011-May 31, 2021. Ministry of Public Safety \& Solicitor General. Retrieved July 2, 2021 from: https://www2.gov.bc.ca/ assets/gov/birth-adoption-death-marriage-and-divorce/deaths/ coroners-service/statistical/illicit-drug.pdf

Butler-McPhee, J., Ka Hon Chu, S., \& van der Meulen, E. (2020). The Good Samaritan Drug Overdose Act: The good, the bad, and the ineffective. Canadian HIV/AIDS Legal Network.

CCSA \& CCENDU (Canadian Centre on Substance Abuse and Canadian Community Epidemiology Network on Drug Use). (2017). CCENDU Bulletin Calling 911 in Drug Poisoning Situations [Bulletin]. Canadian Centre on Substance Abuse. https://www.ccsa.ca/ sites/default/files/2019-04/CCSA-CCENDU-Calling-911-DrugPoisoning-2017-en.pdf

Evans, T. I., Hadland, S. E., Clark, M. A., Green, T. C., \& Marshall, B. D. L. (2016). Factors associated with knowledge of a Good Samaritan Law among young adults who use prescription opioids non-medically. Harm Reduction Journal, 13(1). https://doi.org/10.1186/s12954 016-0113-2

Foldes, F. F., Duncalf, D., \& Kuwabara, S. (1969). The respiratory, circulatory, and narcotic antagonistic effects of nalorphine, levallorphan, and naloxone in anaesthetized subjects. Canadian Anaesthetists Society Journal, 16(2), 151-161. https://doi.org/10.1007/BF03005795

Government of Canada. (2018, October). Good Samaritan Drug Overdose Act: Poster. https://www.canada.ca/en/health-canada/ 
services/publications/healthy-living/good-samaritan-drug-overdoseact-poster.html

Government of Canada. (2019, April). About the Good Samaritan Drug Overdose Act. https://www.canada.ca/en/health-canada/ services/substance-use/problematic-prescription-drug-use/opioids/ about-good-samaritan-drug-overdose-act.html

Government of Canada. (2020, December). Opioid-and Stimulant-related Harms in Canada. https://health-infobase.canada.ca/substancerelated-harms/opioids-stimulants/graphs? index $=587$

Government of Canada. (2021, February 18). Good Samaritan Drug Overdose Act. https://laws.justice.gc.ca/eng/AnnualStatutes/2017_4/ page-1.html\#h-1

Irvine, M. A., Kuo, M., Buxton, J.A., Balshaw, R., Otterstatter, M., Macdougall, L., ... Gilbert, M. (2019). Modelling the combined impact of interventions in averting deaths during a synthetic-opioid overdose epidemic. Addiction, 114(9), 1602-1613. https://doi.org/ 10.1111/add.14664

Jakubowski, A., Kunins, H. V., Huxley-Reicher, Z., \& Siegler, A. (2018). Knowledge of the 911 Good Samaritan Law and 911 -calling behavior of overdose witnesses. Substance Abuse, 39(2), 233-238. https:// doi.org/10.1080/08897077.2017.1387213

Karamouzian, M., Kuo, M., Crabtree, A., \& Buxton, J. A. (2019). Correlates of seeking emergency medical help in the event of an overdose in British Columbia, Canada: Findings from the Take Home Naloxone program. International Journal of Drug Policy, 71, 157-163. https:// doi.org/10.1016/i.drugpo.2019.01.006

Karamouzian, M., Papamihali, K., Graham, B., Crabtree, A., Mill, C. Kuo, M., Young, S., \& Buxton, J. A. (2020). Known fentanyl use among clients of harm reduction sites in British Columbia, Canada. International Journal of Drug Policy, 77. https://doi.org/10.1016/ i.drugpo.2020.102665

Koester, S., Mueller, S. R., Raville, L., Langegger, S., \& Binswanger, I. A. (2017). Why are some people who have received overdose education and naloxone reticent to call Emergency Medical Services in the event of overdose? International Journal of Drug Policy, 48, 115-124. http://dx.doi.org/10.1016/i.drugpo.2017.06.008

Kuo, M., Shamsian, A., Tzemis, D., \& Buxton, J. A. (2014). A drug use survey among clients of harm reduction sites across British Columbia, Canada, 2012. Harm ReductionJournal, 11. https://doi.org/10.1186/ 1477-7517-11-13

Latimore, A. D., \& Bergstein, R. S. (2017). "Caught with a body" yet protected by law? Calling 911 for opioid overdose in the context of the Good Samaritan Law. International Journal of Drug Policy, 50, 82-89. http://dx.doi.org/10.1016/i.drugpo.2017.09.010

Lim, J. K., Bratberg, J. P., Davis, C. S., Green, T. C., \& Walley, A. Y. (2016). Prescribe to prevent: Overdose prevention and naloxone rescue kits for prescribers and pharmacists. Journal of Addiction Medicine, 10(5), 300-308. http://dx.doi.org/10.1097/ADM. 0000000000000223

Mcleod, K. E., Xavier, J., Okhowat, A., Williams, S., Korchinski, M., Young, P., Papamihali, K., Martin, R. E., Monaghan, A., Sharifi, N., \& Buxton, J. A. (2021). Knowledge of the Good Samaritan Drug Overdose Act and possession of a take-home naloxone kit among people recently released from provincial correctional facilities in British Columbia. International Journal of Prison Health, IJPH-04-2021-003. In press

Moustaqim-Barrette, A., Papamihali, K., \& Buxton, J.A. (2019). Take home naloxone program report: Review of data to December 2018. BC Centre for Disease Control. https://towardtheheart.com/resource/ thn-evaluation-report-2019/open

Moustaqim-Barrette, A., Papamihali, K., Crabtree, A., Graham, B., Karamouzian, M., \& Buxton, J. A. (2019). Correlates of take-home naloxone kit possession among people who use drugs in British Columbia: A cross-sectional analysis. Drug and Alcohol Dependence, 205. https://doi.org/10.1016/i.drugalcdep.2019.107609

Nguyen, H., Parker, B. R. (2018). Assessing the effectiveness of New York's 911 Good Samaritan Law-Evidence from a natural experiment. International Journal of Drug Policy. 58, 149-156. https://doi. org/10.1016/i.drugpo.2018.05.013

PIVOT equality lifts everyone. (2017, July 17). The Good Samaritan Drug Overdose Act: What You Need to Know. https://www. pivotlegal.org/ fact_sheet_what_you_need_to_know_about_the_good_samaritan_ drug_overdose_act

Schneider, K. E., Park, J. N., Allen, S. T., Weir, B. W., \& Sherman, S. G. (2020). Knowledge of Good Samaritan Laws and beliefs about arrests among persons who inject drugs a year after policy change in Baltimore, Maryland. Public Health Reports, 135(3), 393-400. https://doi.org/10.1177/0033354920915439

Selfridge, M., Greer, A., Card, K.G., Macdonald, S., \& Pauly, B. (2020). "It's like super structural": Overdose experiences of youth who use drugs and police in three non-metropolitan cities across British Columbia. International Journal of Drug Policy, 76. https://doi. org/10.1016/i.drugpo.2019.102623

Statistics Canada. (2017). Population Centre and Rural Area Classification 2016. https://www.statcan.gc.ca/eng/subjects/standard/pcrac/ 2016/introduction

The R Foundation. (2021). The R Project for Statistical Computing. https:// www.r-project.org/

Watson, D. P., Ray, B., Robison, L., Huynh, P., Sightes, E., Walker, L. S., Brucker, K., \& Duwve, J. (2018). Lay responder naloxone access and Good Samaritan law compliance: Postcard survey results from 20 Indiana counties. Harm Reduction Journal, 15(1). https://doi. org/10.1186/s12954-018-0226-x 